\title{
Differentiation of resource regions of Russia in terms of balanced environmental management
}

\author{
Alexander Semyachkov ${ }^{1 *}$, and Rong Gao ${ }^{1}$ \\ ${ }^{1}$ Institute of Economics of the Ural Branch of Russian Academy of Sciences, Ekaterinburg, 620014, \\ Russia
}

\begin{abstract}
In conditions of natural resource constraints and technogenic destruction of the natural environment, there is a need to improve the mechanisms for managing the natural resource potential in the regions while maintaining a balance between the consumption of natural resources and the preservation of the quality of the environment. The article examines the differentiation of three natural resource regions of the Russian Federation the Ural, Siberian and Far Eastern federal districts - according to the state of the balance of nature management from 1990 to 2018. The subjects of the federation in the Ural, Siberian and Far Eastern federal districts have been identified, with positive and negative use of natural resources for certain types of natural resources: atmospheric, water, forest, land and fuel and energy. The degree of variability in the management of natural resources in these federal districts has been determined. In general, according to the given resources, there is a predominance of "satisfactory" and "positive" nature management in the districts, although according to some indicators there is a "negative" nature management with a clear predominance of the use of resources over their restoration, which predetermines the adoption of cardinal management measures to correct the situation.
\end{abstract}

Keywords: regional differentiation, stable homogeneous, stable heterogeneous, unstable homogeneous, unstable heterogeneous.

\section{Introduction}

In the modern world, the differentiation of resource regions is becoming more and more serious, the ability of nature to restore its resources is not enough to meet the constantly growing needs of mankind in them for carrying out its economic activities. This has become the reason for the emergence of a number of problems: limited natural resources, disruption of the rate of their restoration and quality, diversity and human survival. The problem of depletion of resources periodically arises throughout the history of mankind, but is always solved by human knowledge about the laws of nature and the diversity of the material world. The lack of one resource exists due to ignorance of the properties of another.

Relevance of the work: as a result of the development of human economic activity, a threat arose not only of the deterioration of the quality of nature, but also the question of the

\footnotetext{
*Corresponding author: a.semyachkov@mail.ru
} 
future survival of mankind and the satisfaction of the needs for the consumption of natural resources.

The main goal of this work is to analyze the regional differentiation of resources in three federal districts of Russia (Ural, Siberian and Far Eastern).

Research objectives: choice of environmental and economic indicators and methods of their processing; assessment of variability of time series of ecological and economic indicators of resource regions; assess the managed and unmanaged environmental and economic indicators of resource regions.

\section{Material and Methods}

According to the statistical characteristics of the correlation coefficient, controlled - when cash injections in the protection of natural resources, natural resources are effectively (artificially) restored. unmanageable - when cash injections to protect natural resources, natural resources are not efficiently (artificially) restored.

According to the statistical characteristics of the series, there are four types of time series - stably homogeneous and heterogeneous, and unstable homogeneous and heterogeneous. [1, 4].

Characteristics of a stable time series:

- the average value is constant, and the series fluctuates around the average value;

- autocovariance depends only on the time interval;

- for most stationary series, the autocorrelation function decreases rapidly as the lag term increases.

Characteristics of unstable time series:

- does not have a fixed average;

- autocovariance depends not only on the time interval;

- as the delay time increases, the autocorrelation function usually does not decay quickly $[2,3]$.

Characteristics of homogeneous time series:

- standard deviation and other scattering indices are constant;

- time series can be both stable and unstable [5, 6].

Characteristics of heterogeneous time series:

- standard deviation and other scattering indices are not constant;

- time series can be both stable and unstable [7, 8].

The balance of nature management is determined by the relationship of certain indicators characterizing a certain type of natural resources: atmospheric, water and forest. At the same time, indicators can characterize both the use of natural resources, for example, the use of fresh water or wood production, and the restoration of natural resources (the volume of recycled and consistently used water, reforestation, etc.). Since 1991, the Russian Federation has been keeping records of environmental and economic indicators in statistical reporting with an observation period of 27-28 years. All numerical values are taken from official sources, namely: the Unified Interdepartmental Information and Statistical System (EMISS) and the Rosstat (https://rosstat.gov.ru/).

The research method determines important links between indicators of the ecological state, analyzing the correlation coefficient and the coefficient of variation between ecological and economic indicators, and allows to obtain the results and tendencies of natural resource management in resource regions.

The influence of the indicator is manifested in the presence of a connection, which is characterized by the correlation coefficient. For $|r| \geqslant 0.5$ the indicator acts, with $|r|<0.5$ there is no connection $[9,10]$. 
Thus, it is possible to determine the state of change of natural resources in time, unstable at $|\mathrm{r}| \geqslant 0.5$ and stable at $|\mathrm{r}|<0.5$, non-uniform at $\mathrm{v}>0.5$ and homogeneous at $\mathrm{v}<0.5$.

\section{Results}

In the course of this work, the ecological and economic indicators of the subjects of the federation of three federal districts were examined and studied in detail: the Ural, Siberian and Far Eastern regions, their controllability and uncontrollability, stability and instability, homogeneity or heterogeneity were analyzed.

Atmospheric resources: in the Ural Federal District in all districts the resource is managed by $100 \%$, while in the Siberian and Far Eastern Federal Districts this indicator is almost two times less. In these three federal districts, the management of the use and restoration of atmospheric resources has a negative correlation on average in $16 \%$ of districts, a satisfactory correlation in $37 \%$ of districts, and a positive correlation in $47 \%$. On average, $18 \%$ of districts have a stable-homogeneous degree of variability $(\mathrm{SH})$, a stable-heterogeneous $(\mathrm{SHe})-$ on average $24 \%$, an unstable-homogeneous (UH) - on average $25 \%$ and an unstableheterogeneous (UHe) - an average of $34 \%$ districts of these districts (Table 1).

Table. 1. Number of Regions with Air Resources Management, \%.

\begin{tabular}{|l|l|l|l|l|l|l|l|l|l|}
\hline $\begin{array}{c}\text { Federal } \\
\text { district }\end{array}$ & Control & Uncontrollable & Negative & Satisfactory & Positive & SH & SHe & UH & UHe \\
\hline Ural & 100 & 0 & 12.5 & 29.0 & 58.0 & 17 & 17.0 & 21.0 & 46 \\
\hline Siberia & 50 & 50 & 20.0 & 37.5 & 42.5 & 25 & 22.5 & 22.5 & 30 \\
\hline Far East & 64 & 36 & 16.0 & 43.0 & 41.0 & 11 & 32.0 & 30.0 & 27 \\
\hline Average & - & - & 16.0 & 37.0 & 47.0 & 18 & 24.0 & 25.0 & 34 \\
\hline
\end{tabular}

Water resources: almost all water resources in the Ural Federal District are managed, while in the Siberian and Far Eastern Federal Districts this resource is not properly managed. In these three federal districts, the management of the use and restoration of water resources has a negative correlation on average in $15 \%$ of districts, a satisfactory correlation in $34 \%$ of districts, and a positive correlation in $51 \%$. On average, $22 \%$ of districts have a stablehomogeneous degree of variability $(\mathrm{SH})$, a stable-heterogeneous $(\mathrm{SHe})-$ on average $12 \%$, unstable-homogeneous (UH) - on average $34 \%$ and an unstable-heterogeneous (UHe) - on average $33 \%$ districts of these districts (Table 2) .

Table. 2. Number of regions with water resources management, $\%$.

\begin{tabular}{|l|l|l|l|l|l|l|l|l|l|}
\hline $\begin{array}{c}\text { Federal } \\
\text { district }\end{array}$ & Control & Uncontrollable & Negative & Satisfactory & Positive & SH & SHe & UH & UHe \\
\hline Ural & 83 & 17 & 23 & 37 & 40 & 20 & 17 & 40 & 23 \\
\hline Siberia & 50 & 50 & 8 & 26 & 66 & 18 & 8 & 34 & 40 \\
\hline Far East & 55 & 45 & 15 & 38 & 47 & 27 & 11 & 27 & 35 \\
\hline Average & - & - & 15 & 34 & 51 & 22 & 12 & 34 & 33 \\
\hline
\end{tabular}

Forest resources: practically managed in all three federal districts. In these three federal districts, the management of the use and restoration of atmospheric resources has a negative correlation on average in $15 \%$ of districts, a satisfactory correlation in $28 \%$ of districts, and a positive correlation in 57\%. Stable-homogeneous degree of variability $(\mathrm{SH})$ has an average of $11 \%$, stable-heterogeneous (SHe) - on average $17 \%$, unstable-homogeneous (UH) - on average $43 \%$ and unstable-heterogeneous ( $\mathrm{UHe}$ ) - on average $28 \%$ of areas these counties (Table 3). 
Table. 3. Number of regions with forest management, $\%$.

\begin{tabular}{|l|l|l|l|l|l|l|l|l|l|}
\hline $\begin{array}{c}\text { Federal } \\
\text { district }\end{array}$ & Control & Uncontrollable & Negative & Satisfactory & Positive & SH & SHe & UH & UHe \\
\hline Ural & 100 & 0 & 12 & 31 & 57 & 12 & 19 & 36 & 33 \\
\hline Siberia & 90 & 10 & 14 & 24 & 61 & 11 & 13 & 47 & 29 \\
\hline Far East & 91 & 9 & 18 & 30 & 52 & 10 & 19 & 47 & 23 \\
\hline Average & - & - & 15 & 28 & 57 & 11 & 17 & 43 & 28 \\
\hline
\end{tabular}

Land resources: are managed by $100 \%$ in the Ural Federal District, in the Siberian Federal District by $80 \%$, but are unmanaged in the Far Eastern Federal District. In these three federal districts, the management of the use and restoration of atmospheric resources has a negative correlation on average of $30 \%$, a satisfactory correlation $-47 \%$, and a positive $-23 \%$. On average, $33 \%$ of regions have a stable-homogeneous degree of variability $(\mathrm{SH})$, a stableheterogeneous ( $\mathrm{SHe}$ ) - on average $10 \%$, an unstable-homogeneous (UH) - an average of $33 \%$ and an unstable-heterogeneous (UHe) - an average of $24 \%$ districts of these districts (Table 4).

Table. 4. Number of regions with land administration, $\%$.

\begin{tabular}{|l|l|l|l|l|l|l|l|l|l|}
\hline $\begin{array}{c}\text { Federal } \\
\text { district }\end{array}$ & Control & Uncontrollable & Negative & Satisfactory & Positive & SH & SHe & UH & UHe \\
\hline Ural & 100 & 0 & 30 & 43 & 27 & 27 & 7 & 43 & 23 \\
\hline Siberia & 80 & 20 & 34 & 46 & 20 & 38 & 8 & 30 & 24 \\
\hline Far East & 64 & 36 & 25 & 53 & 22 & 35 & 16 & 25 & 24 \\
\hline Average & - & - & 30 & 47 & 23 & 33 & 10 & 33 & 24 \\
\hline
\end{tabular}

Fuel and energy resources: poor governance is observed in all three federal districts. In these three federal districts, the management of the use and restoration of atmospheric resources has a negative correlation on average of $28 \%$, a satisfactory correlation $-42 \%$, and a positive $-30 \%$. On average, $19 \%$ of regions have a stable-homogeneous degree of variability $(\mathrm{SH})$, a stable-heterogeneous $(\mathrm{SHe})$ - on average $23 \%$, unstable-homogeneous $(\mathrm{UH})$ - on average $24 \%$ and an unstable-heterogeneous (UHe) - an average of $34 \%$ districts of these districts (Table 5).

Table. 5. Number of regions with fuel and energy resources management, $\%$.

\begin{tabular}{|l|l|l|l|l|l|l|l|l|l|}
\hline $\begin{array}{c}\text { Federal } \\
\text { district }\end{array}$ & Control & Uncontrollable & Negative & Satisfactory & Positive & SH & SHe & UH & UHe \\
\hline Ural & 20 & 80 & 7 & 64 & 29 & 36 & 36 & 14 & 14 \\
\hline Siberia & 22 & 78 & 48 & 39 & 13 & 4 & 26 & 22 & 48 \\
\hline Far East & 27 & 73 & 28 & 24 & 48 & 16 & 8 & 36 & 40 \\
\hline Average & - & - & 28 & 42 & 30 & 19 & 23 & 24 & 34 \\
\hline
\end{tabular}

\section{Conclusion}

Based on the results of the research carried out, the following theoretical and methodological conclusions can be drawn: (a) The general theory of spatio-temporal variability can be applied to assess the variability of time series of environmental and economic indicators; (b) Typification of ecological and economic indicators by types of variability, including stable, unstable, homogeneous, heterogeneous and their combinations by resource regions can be an assessment of the balance of nature management.

Based on the results, it can be concluded that different levels of resource management in different regions have led to regional differentiation in the resource constituent entities of the Russian Federation. The balance of environmental management for various types of 
resources is determined by the relationship between the corresponding indicators, which also predetermines the adoption of managerial decisions in the use of natural resources in the region.

Thus, we can conclude that it is possible to use this method as an additional toolkit for environmental management on the territory of natural resource regions, for the rational consumption of resources within the framework of sustainable development, which in turn will lead to the stable and safe development of human society, to meet its needs, maintaining the quality and well-being of the environment.

\section{References}

1. G. K. Bondarik, Foundations of the theory of variability of engineering-geological properties of rocks (Nedra, Moscow, 1971)

2. M. Wang, Time series and spatial dimension studies (Capital University of Economics, Beijing, 2011)

3. X. Li, Investigation of a method for modeling non-stationary time series (Wuhan University of Technology, Wuhan, 2005)

4. L. Zhao, Study of the method of periodic analysis of hydrological time series (He Hai University, Nanjing, 2007)

5. J. Zhu, Distribution characteristics and forecasting of time series (Nanjing University of Information Technology, Nanjing, 2010)

6. C. Yu, Study of the estimation of the parameters of the time series model based on a stable distribution (Harbin University of Science and Technology, Harbin, 2014)

7. B. Xu, Journal of Geomatics 1, 64-69 (2016)

8. Y. Wang, Application of time series analysis (Renmin University of China, Beijing, 2005)

9. A. I. Semyachkov, A. A. Terekhanov, Fundamentals of scientific research in geoecology (Ural State Mining University, Ekaterinburg, 2015)

10. G. Chen, Modern Information Technology 13, 54-65 (2020) 